\title{
LANGUAGE AS ACTION
}

\begin{abstract}
Maurice Nevile, University of Canberra
Maurice Nevile is a research fellow in the Division of Communication and Education at the University of Canberra. His recent research interests include interaction in the airline cockpit, communication as a factor in aviation accidents, talk radio, and the in-venue conduct of problem gamblers. He is author of Beyond the Black Box: Talk-in-Interaction in the Airline Cockpit (Ashgate, 2004), in the series Directions in Ethnomethodology and Conversation Analysis, and is co-author of Making the Most of Your Arts Degree (Longman, 1994).

Correspondence to Maurice Nevile: Maurice.Nevile@canberra.edu.au

Johanna Rendle-Short, The Australian National University

Johanna Rendle-Short is senior lecturer in Linguistics and Applied Linguistics at the Australian National University, Canberra. Her main research interest is conversation analysis, talk-in-interaction and embodied discourse. She is the author of The Academic Presentation: Situated Talk in Action (Ashgate, 2006), in the series Directions in Ethnomethodology and Conversation Analysis. More recently she has been analysing the use of address terms in the Australian political news interview, as well as the interaction of children with communication disorders.

Correspondence to Johanna Rendle-Short: Johanna.Rendle-Short@anu.edu.au
\end{abstract}

\section{INTRODUCTION}

The theme of this Special Issue, 'language as action', reflects the contributors' interest in what, and how, people do things with language, and particularly spoken language. The papers here have in common a concern for investigating language-in-use in ordinary social life, and how language can both shape, and be shaped by, its use in particular social settings. More specifically, the papers share the interest of conversation analysis (CA) in the language of real-time naturally occurring interaction, for uncovering the practices and processes of reasoning by which participants create and make sense of what it is they are doing, of what is going on. Schegloff $(1996,2006)$ has argued that interaction is the primordial site of sociality, and is 'the infrastructure for social institutions, the natural ecological niche for language, and the arena in which culture is enacted' (Schegloff 2006: 70). CA examines the ordinary and situated taken-for-granted language competencies by which participants accomplish sociality. An interest in the place of language in social life can take many forms within sociolinguistics and discourse analysis, and such language might be theorised in many ways (Coupland, Sarangi and Candlin 2001). CA's particular focus, reflected in the papers here, is to avoid theoretical descriptions and instead engage with the details of 'language as action' in participants' own local 
('here-and-now' or 'there-and-then') management of interaction as sequentially organised talk.

In different ways, each paper in this Special Issue explores how language, or talk-ininteraction, accomplishes action. So what do we mean by action? We mean that people talk to each other to construct and order the affairs of their ordinary social activities, to act in social identities and roles, to form and maintain social relationships and group memberships, or formal and recognisable organisations and institutions, or to collaborate for work. As Austin (1962) put it, we do things with words. We might ask or answer a question, agree, disagree, tell, explain, announce or acknowledge, assess, doubt, request, offer, demand, complain, invite, accept, decline, compliment, criticise, acknowledge, thank, apologise, greet, joke, praise, insult, notice, ignore, or anything else, and we do so in the course of jointly participating with others to manage the processes of interaction itself. How do participants, in situ, determine what the other person is doing by saying this or that, in just those words, in just this way, at just this moment in this interaction (Schegloff 2006)? CA considers the social action underway, by showing how the design and timing of talk is sensitive to its placement in the sequential organisation of real time interaction and activity. Participants within interaction, therefore, design and coordinate their utterances in order to meet the contingencies of the moment and to be recognised and carried off for what they are, for particular social ends, and with real social consequences. So, language in interaction is not a simple transmitter of information, but is a means of accomplishing social action (Wooffitt 2005). The analytic focus is not on language as tool to allow something else to occur, but on language as action, where the language used is itself the something that is occurring. It is through detailed analysis of the moment-to-moment talk that it is possible to see this something, to focus on language as the reality, as the social action underway.

This issue presents a sample of current CA work in Australia. Our aim is to show what CA-grounded research can look like, and to highlight its potential relevance to Australian researchers in applied linguistics. The contributors are all active researchers in Australia, and their papers have in common that they use Australian data. The papers analyse 'language as action' across a range of settings and situations: calls to a child support help line, turn-taking in mixed language conversation of indigenous women, managing interactional difficulties when talking to hearing-impaired participants, asking women in the demographic survey interview about the likelihood of having more children, using response tokens in parent-child interaction, and attributions and categorisations of personal identity. We will first outline the nature and development of CA, and how spoken language can be represented through detailed transcriptions from recordings of 
naturally-occurring interaction. We then describe links between CA and applied linguistics, before finally introducing the papers of this issue.

\section{CONVERSATION ANALYSIS}

CA's origins are in sociology, and are usually traced to a paper on the organisation of turn-taking for conversation, written in the mid-1970s (Sacks, Schegloff and Jefferson 1974). The early development of conversation analysis is especially associated with the ideas of Harvey Sacks (see Sacks 1992, and discussion by Silverman 1998), and the influence within sociology of Harold Garfinkel and ethnomethodology (for recent introductions see Francis and Hester 2004; ten Have 2004). A basic principle of conversation analysis is that naturally occurring talk is systematically organised, and that its organisation is both discoverable and significant for understanding social order (Goodwin and Heritage 1990; Sacks, Schegloff and Jefferson 1974). Although talk might initially look messy and full of stops and starts, through detailed analysis it is possible to 'see' and explicate its organisational principles. For example, it can be shown that even the ums and $u h s$ or other possible 'hitches' or 'speech problems' do not occur randomly throughout talk. Rather, there is systematicity to their occurrence that can be shown to be significant for how participants organise their talk as social action, for how participants themselves create and demonstrate their understandings of what is going on.

$\mathrm{CA}$ emphasises the value of considering much more than the content of talk. Attention to the details of just how talk is produced and placed within the sequential flow of interaction is revelatory of what people are doing. At the core of CA is the notion that people exhibit, in the design and timing of their own talk and conduct, their understanding and treatment of others' prior talk and conduct. For this reason, conversation analysis focuses on the sequential development of interaction, on seeing what happens and what happens next. The basic guiding question for analysts of naturally-occurring interaction becomes why that now? (Schegloff and Sacks 1973).

Key areas for the focus of conversation analysis over the past 30 years include turntaking, turn design, word selection, laughter, moments when participants speak simultaneously (overlapping talk), how participants manage interactional difficulties (repair), and the organisation of talk into sequences and larger courses of action. In spite of its name, conversation analysis is not only interested in ordinary conversation, such as between friends and family. It is a form of social enquiry that addresses all forms of interaction, including in institutions and workplaces, such as between doctor and patient, in the classroom, in the media, in academic discourse, or talk involving L1 and L2 
speakers. CA studies now also increasingly address participants' non-verbal (embodied) contributions to interaction, including gaze, body posture and positioning, gestures, facial expressions, use of artefacts, and spatial orientation within the physical setting.

Detailed introductions to the origins, principles, and methods of conversation analysis, include Goodwin and Heritage (1990), Hutchby and Wooffitt (1998), Pomerantz and Fehr (1997), Psathas (1995), ten Have (1999), Drew (2005), and Schegloff (2006), while Schegloff (2007) gives a significant account of sequence organisation. A new four-volume publication (Drew and Heritage 2006) provides a collected overview of key papers for major CA themes, and Atkinson and Heritage (1984) and Lerner (2004) offer collections of early papers. Discussion or collections of CA work on institutional talk include Drew and Heritage (1992), Heath and Luff (2000), McHoul and Rapley (2001), Arminen (2005), Heritage (2005), Richards and Seedhouse (2005), and Heritage and Maynard (2006).

\section{TRANSCRIPTION}

The primary data for CA are audio or video recordings of people interacting in naturallyoccurring settings, rather than invented, isolated, or coded examples. This is one of the main features distinguishing CA from other linguistic approaches to the analysis of discourse that tend to be more interested in understanding language within the social context in which it is produced, rather than focusing on 'language as action' as demonstrated through speakers' interaction with each other in real time. Conversation analysts represent such data through detailed transcription. CA transcripts, however, do not simply provide information concerning the content of the talk (as do other more basic transcripts), but include details of just how it is that moment-by-moment participants locally manage the process of interaction. In other words, CA transcripts can provide detail concerning a) what is being said, b) how it is being said, and c) what the hearer (recipient) is doing while it is being said. The aim is to transcribe the talk in sufficient detail so that analysts can 'see' the process of interaction, thereby capturing the here-and-now (or there-andthen) detail that was available to, and used by, the participants themselves. Conversation analysis transcriptions do not show grammatically correct sentences that speakers should have said, but include the partial ungrammatical sentences, incomplete words, little words such as okay or yeah, that participants actually said. Transcriptions also indicate, for example, audible in-breaths and out-breaths, intonation contours, relative speed and loudness of talk, ums and $u h s$, the presence and length of pauses, and overlapping talk 
(simultaneous with other talk). It is necessary also to consider the recipient's (hearer's) conduct, for example the presence of response tokens such as $m b m, u b$ hub or yeah.

CA studies have shown how such features of talk are significant for the participants themselves, for how they understand and contribute to what is happening. Such details impact the nature and course of interaction, what the participants $d o$. The rationale behind detailed transcription is that if all talk is ordered, one cannot dismiss any aspect of talk as being too insignificant or unworthy of analysis (Sacks, Schegloff and Jefferson 1974). As a result, conversation analysts have developed transcription conventions that allow for detailed representation of talk. Originally a system for transcription was developed by Gail Jefferson. Over the years this system has been further developed (e.g. see ten Have 1999; Gardner 2001; Lerner 2004). Table 1 outlines some of the main conversation analysis transcription conventions.

\begin{tabular}{|c|c|}
\hline hello. & falling terminal intonation \\
\hline hello, & slight rising intonation \\
\hline helloi & rising intonation, weaker than that indicated by a question mark \\
\hline hello? & strongly rising intonation \\
\hline hel- & talk that is cut off \\
\hline$>$ hello $<$ & talk is faster than surrounding talk \\
\hline$<$ hello> & talk is slower than surrounding talk \\
\hline HELLO & talk is louder than surrounding talk \\
\hline${ }^{\circ}$ hello ${ }^{\circ}$ & talk is quieter than surrounding talk \\
\hline$\uparrow$ or $\downarrow$ & marked rising or falling shifts in pitch \\
\hline he::llo & lengthening of a sound or syllable \\
\hline hello & emphasis \\
\hline$(1.0),(0.3)$ & timed intervals (silence), in seconds and tenths of seconds \\
\hline$()$. & short untimed pause, less than 0.2 of a second \\
\hline.$h h$ & audible inhalations \\
\hline $\mathrm{hh}$ & audible exhalations \\
\hline * & creaky voice \\
\hline$=$ & latched talk - talk following previous talk with no gap \\
\hline$[\quad]$ & simultaneous/overlapping talk \\
\hline ) & transcriber uncertainty \\
\hline
\end{tabular}

Table 1 Common conversation analysis transcription conventions 
An important feature of the CA transcription conventions is that conventional punctuation marks are used to represent intonation features and patterns rather than grammatical sentence structure. In this way it is possible to capture information concerning how speakers talk, and its significance for revealing what participants do. For example, the full stop representing falling intonation is not only found at the end of grammatically correct sentences - it may occur mid-utterance, indicating that a particular word (or phrase) is said with falling intonation (e.g. 'she's gone. overseas.'). Correspondingly, a comma does not mark grammatical structure, but indicates a slight rise in intonation, as may be found at the end of an utterance (e.g. 'she was running, before she fell,') or following a response token (e.g. 'okay,' or 'mm,').

It is also important to note that in CA the activity of transcribing is not merely a mundane task to be completed before analysing the data. By repeated listening to recordings and detailing what participants are doing, the analyst is best able to understand the nature of the interaction, and what it can reveal of social life as the participants themselves created and experienced it.

Transcription is not a task that can be rushed through or skipped over; transcription is a key part of the analytic process. As a process, transcription shows seemingly messy spoken language to be structured and finely ordered sequences of talk.

\section{CONVERSATION ANALYSIS AND APPLIED LINGUISTICS}

Applied linguistics (AL) is a broad discipline that covers a multitude of areas (Davies and Elder 2004), including: second language (L2) interaction, multilingual talk, grammar and interaction, talk in educational contexts, language pedagogy, assessment, and intercultural communication. AL covers much more than teaching and learning. As a microanalytic approach to language in use, to discourse and practices in naturally occurring interaction, research in CA is important for developing a diversity of interests in applied linguistics. Many applied linguistics researchers, for example Grabe (2004), Brumfit (1997) and Larsen-Freeman (1997), have argued for the value of applied linguistics research to resolve language-based problems of society. Brumfit (2004: 134-135) notes that applied linguistics is 'recognisably an exploration of language practices and of realworld problems in which language is central'. Over more than three decades, ethnomethodology and CA have contributed significantly to such an emphasis, and such goals, in

applied linguistics, whether that be in the classroom setting or as a way of understanding real world issues and problems. 
Many recent articles and books have directly linked CA and AL. For example, the recent Blackwell Handbook on Applied Linguistics volume (Davies and Elder 2004) includes a contribution by Gardner (2004) on conversation analysis. In an overview of CA's relation to AL, Schegloff et al. (2002) argue that CA touches on concerns of applied linguists at many points, including native, non-native, and multilingual talk; talk in educational institutions; grammar and interaction; intercultural communication and comparative $\mathrm{CA}$; and in assessing the implications for designing language teaching tasks, materials, and assessment tasks. One important contribution to AL is CA's challenge to traditional notions of communicative competence (e.g. Canale 1983; Canale and Swain 1980) by focussing on what it means for an L2 speaker to be conversationally competent in a second language (e.g. Wagner 1996). Markee (2000), for example, takes an applied linguistic perspective to a CA framework to argue for the importance of interactional competence as a collaborative, socially constituted domain of communicative competence. Firth and Wagner $(1997,1998)$ in the Modern Language Journal, have also used CA to critique second language acquisition methodology, through a discussion of how to categorise or label L2 speakers. In addition, in an edited volume on CA and second language conversations within the Advances in Applied Linguistics series, Gardner and Wagner (2004) challenge traditional models of understanding L2 speakers as being in some way deficient, and instead focus on the interactional accomplishments of L2 speakers. This volume is a good example of the recent work arising out of CA and AL, as is Seedhouse (2004), who examines interaction within the language classroom from a CA perspective.

The Australian Review of Applied Linguistics (ARAL) has itself also published a number of CA-informed papers over the years, for example, Emmison (1993), Smith (1996), Barraja-Rohan (1997), Filipi (1998), Liddicoat and Döpke (1998), Gardner (2000), So'o and Liddicoat (2000), Ardington (2003), Nevile (2002, 2005), and RendleShort $(1999,2003)$. ARAL has also published a Special Issue titled Spoken Interaction Studies in Australia (Gardner 1994), with a number of contributors drawing on CA influences, for example, on the use of turn-taking resources in Khmer-Australian English conversation (Astbury 1994), on a very delayed acceptance to an invitation in a French conversation (Barraja-Rohan 1994), on preference organisation in teacher-supervision talk (Taylor 1994), on the role of expansion sequences in an Italian oral test (Filipi 1994), and on closing calls in talkback radio (Döpke et al. 1994).

This current issue is timely. CA is developing as a prominent methodology for social science research (see Drew, Raymond and Weinberg 2006), and especially for cross-disciplinary research. Thus, CA is increasingly influencing research in a number of academic fields, not just in linguistics, applied linguistics and sociology, but also in education, 
psychology, anthropology, and communication studies. CA is also often drawn on by researchers coming from, and primarily committed to, a specific area of institutional (professional) practice (e.g. law, nursing). In addition, there has been, in recent years, a significant growing interest in CA from international book publishers (e.g. Cambridge University Press, John Benjamins, Lawrence Erlbaum, Oxford University Press, Sage). Ashgate Publishing in the UK has recently launched a new series titled Directions in Ethnomethodology and Conversation Analysis, which has so far produced three volumes (Nevile 2004, Arminen 2005, Rendle-Short 2006), with another in press (Francis and Hester in press). Apart from a previous $A R A L$ volume (Gardner 1994), there is no other edited collection of CA research in Australia.

\section{CURRENT ISSUE}

In various ways, and representing a variety of settings, each paper examines 'language as action'. Emmison and Danby focus on calls to Kids Help Line, a national Australian counselling service for children and young people. They seek to address the issue of how counsellors determine the authenticity of the call, in order to distinguish between possible 'prank' callers who are simply ringing for fun or to test the service, and genuine requests for help or support. They show how in the case of the 'prank' call, both caller and counsellor collaborate to make the call a success, with the caller trying to 'get away with' the call as long as possible while making sure that the counsellor knows that it is a prank, and the counsellor respectfully and skilfully acknowledging that it is a prank without prematurely terminating the call. May focuses on interviews for an Australian demographic telephone survey, called Negotiating the Life Course, in which women are asked about their likelihood of having children. She shows how 'troubled' interviews, in which interviewees are not sure how to respond when asked whether or not they intend to have more children, have a characteristic structure and take longer than interviews in which interviewees are clear about their response. Filipi examines the actions accomplished by the response tokens $m m$ and $m m ~ h m$ in the interactions of a parent and his daughter aged $0 ; 10-2 ; 0$. She shows that $m m$ accomplished a range of functions based on its sequential placement and prosodic features, whereas $\mathrm{mm} \mathrm{hm}$ is much more restricted to its use as a continuer. She discusses how the child's emerging knowledge and understanding of response tokens can be revealed through detailed analysis of talk-in-interaction. Skelt focuses on problems of understanding that might arise when listening to someone who has a hearing impairment. Instead of simply repairing problems as they arise, she shows how another possibility is to collaboratively close the problematic part of the conversation. 
The paper examines how the interactants successfully and collaboratively close down a topic in such a way as to avoid possible threats to face and identity. Gardner and Mushin present an analysis of overlap (simultaneous talk) in the mixed (Garrwa, Kriol and English) language conversations of two indigenous Australian women, as part of a larger study of turn-taking practices in indigenous conversations. They show the overwhelmingly orderliness of the turn-taking, with any deviations from orderliness being mostly accounted for by the speakers' orientation to points of possible turn completion and rules of turn-taking, as described by Sacks, Schegloff and Jefferson (1974). Austin and Fitzgerald examine personal identity through the way in which an interviewee resists the possible accusation of being 'a bad mother' by instead positing her mothering as 'ordinary'. Using Membership Category Analysis they analyse the way in which claims and counterclaims are routinely grounded in descriptions and accounts, and embedded in shifts between individual and categorial actions.

We are delighted to be able to present this issue, and we thank the contributors, and the ARAL editor Roly Sussex and editorial team, and former ARAL editor Antonia Rubino, for making it possible.

\section{Maurice Nevile and Johanna Rendle-Short}

Guest Editors, ARAL special thematic issue Language as Action: Australian Studies in Conversation Analysis

\section{REFERENCES}

Ardington, A. M. 2003. 'Alliance building in girls' talk: A conversational accomplishment of playful negotiation'. Australian Review of Applied Linguistics 26 (1): 38-54.

Arminen, I. 2005. Institutional Interaction: Studies of Talk at Work. Aldershot: Ashgate.

Astbury, V. 1994. 'The use of turn-taking resources in a Khmer-Australian English conversation'. In Spoken Interaction Studies in Australia, edited by Gardner, R. Australian Review of Applied Linguistics Series S 11: 173-184. Melbourne: Applied Linguistics Association of Australia.

Atkinson, J. M.; Heritage. J., editors. 1984. Structures of Social Action: Studies in Conversation Analysis. Cambridge: Cambridge University Press.

Austin, J. L. 1962. How to Do Things with Words. Oxford: Oxford University Press.

Barraja-Rohan, A. M. 1994. 'A very delayed acceptance to an invitation in a French conversation'. In Spoken Interaction Studies in Australia, edited by Gardner, R. Australian Review of Applied Linguistics Series S 11: 153-172. Melbourne: Applied Linguistics Association of Australia. 
Barraja-Rohan, A. M. 1997. 'Teaching conversation and sociocultural norms with conversation analysis'. In Teaching Language Teaching Culture, edited by Liddicoat, A. J. and Crozet, C. Australian Review of Applied Linguistics Series S 14. Melbourne: Applied Linguistics Association of Australia.

Brumfit, C. 1997. 'Theoretical practice: Applied linguistics as pure and practical science'. In Applied Linguistics Across Disciplines, edited by Mauranen, A. and Sajavaara, K. AILA Review 12 1995/6: 18-30.

Brumfit, C. 2004. 'Applied linguistics in 2004. Unity in diversity?' In World Applied Linguistics. A Celebration of 40 Years of AILA, edited by Gass, S. M. and Makoni, S. AILA Review 17: 133-136.

Canale, M. 1983. 'From communicative competence to communicative language pedagogy'. In Language and Communication, edited by Richards, J. C. and Schmidt, R. W. New York: Longman.

Canale, M.; Swain, M. 1980. 'Theoretical bases of communicative approaches to second language teaching and testing'. Applied Linguistics 1: 1-47.

Coupland, N.; Sarangi, S.; Candlin, C. N., editors. 2001. Sociolinguistics and Social Theory. London: Pearson.

Davies, A.; Elder, C., editors. 2004. The Handbook of Applied Linguistics. Malden, USA: Blackwell Publishing Ltd.

Döpke, S.; Brown, A.; Liddicoat, A.; Love, K. 1994. 'Closings in talkback radio: Institutional effects on conversational routines'. In Spoken Interaction Studies in Australia, edited by Gardner, R. Australian Review of Applied Linguistics Series S 11: 21-46. Melbourne: Applied Linguistics Association of Australia.

Drew, P. 2005. 'Conversation analysis'. In Handbook of Language and Social Interaction, edited by Fitch, K. L. and Sanders, R. E. Mahwah, NJ: Lawrence Erlbaum.

Drew, P.; Heritage, J., editors. 1992. Talk at Work: Interaction in Institutional Settings. Cambridge: Cambridge University Press.

Drew, P.; Heritage, J., editors. 2006. Conversation Analysis. Four Volumes. London: Sage.

Drew, P.; Raymond, G.; Weinberg, D., editors. 2006. Talk and Interaction in Social Research Methods. London: Sage.

Emmison, M. 1993. 'On the analyzability of conversational fabrication: A conceptual inquiry and single case example’. Australian Review of Applied Linguistics 16 (1): 83-108.

Filipi, A. 1994. 'Interaction in an Italian oral test: The role of some expansion sequences'. In Spoken Interaction Studies in Australia, edited by Gardner, R. Australian Review of Applied Linguistics Series S 11: 119-136. Melbourne: Applied Linguistics Association of Australia.

Filipi, A. 1998. 'Interaction or interrogation? A study of talk occurring in a sample of the 1992 VCE Italian oral common assessment talk (Cat 2)'. Australian Review of Applied Linguistics 21 (2): 123-137.

Firth, A.; Wagner, J. 1997. 'On discourse, communication, and (some) fundamental concepts in second language acquisition research'. Modern Language Journal 81 (3): 285-300. 
Firth, A.; Wagner, J. 1998. 'SLA property: No trespassing! A reply'. Modern Language Journal 82 (1): 91-94.

Francis, D.; Hester, S. 2004. An Invitation to Ethnomethodology: Language, Society and Social Interaction. London: Sage.

Francis, D.; Hester, S. In press. Orders of Ordinary Action: Respecifying Sociological Knowledge. Aldershot: Ashgate.

Gardner, R., editor. 1994. Spoken Interaction Studies in Australia. Australian Review of Applied Linguistics Series S 11. Melbourne: Applied Linguistics Association of Australia.

Gardner, R. 2000. 'Resources for delicate manoeuvres: Learning to disagree'. In Discourse Analysis and Language Teaching, edited by Soler, E. A. and Guzman, J. R. Australian Review of Applied Linguistics Series S 16. Melbourne: Applied Linguistics Association of Australia.

Gardner, R. 2001. When Listeners Talk: Response Tokens and Listener Stance. Amsterdam/Philadelphia: John Benjamins.

Gardner, R. 2004. 'Conversation analysis'. In The Handbook of Applied Linguistics, edited by Davies, A. and Elder, C. Malden, USA: Blackwell Publishing Ltd.

Gardner, R.; Wagner, J., editors. 2004. Second Language Conversations. London: Continuum.

Goodwin, C.; Heritage, J. 1990. 'Conversation analysis'. Annual Review of Anthropology 19: 283-307.

Grabe, W. 2004. 'Perspectives in applied linguistics: A North American view'. In World Applied Linguistics. A Celebration of 40 Years of AILA, edited by Gass, S. M. and Makoni, S. AILA Review 17: 105-132. Amsterdam/Philadelphia: John Benjamins.

Have, P., ten. 1999. Doing Conversation Analysis: A Practical Guide. London: Sage.

Have, P., ten. 2004. Understanding Qualitative Research and Ethnomethodology. London: Sage.

Heath, C.; Luff, P. 2000. Technology in Action. Cambridge: Cambridge University Press.

Heritage, J. 2005. 'Conversation analysis and institutional talk'. In Handbook of Language and Social Interaction, edited by Fitch, K. L.; Sanders, R. E. Mahwah, NJ: Lawrence Erlbaum.

Heritage, J.; Maynard, D. 2006. Communication in Medical Care: Interaction Between Primary Care Physicians and Patients. Cambridge: Cambridge University Press.

Hutchby, I.; Wooffitt, R. 1998. Conversation Analysis: Principles, Practices and Applications. Cambridge: Polity.

Larsen-Freeman, D. 1997. 'Impressions of AILA 1996'. In Applied Linguistics Across Disciplines, edited by Mauranen, A.; Sajavaara, K. AILA Review 12 1995-06: 87-92. Milton Keynes: AILA.

Lerner, G. H., editor. 2004. Conversation Analysis: Studies From the First Generation. Amsterdam/Philadelphia: John Benjamins.

Liddicoat, A.; Döpke, S. 1998. 'The structure of callers' contributions in talkback radio'. Australian Review of Applied Linguistics 21 (2): 79-104.

Markee, N. 2000. Conversation Analysis. Mahweh, NJ: Lawrence Erlbaum.

McHoul, A.; Rapley, M., editors. 2001. How to Analyse Talk in Institutional Settings. London: Continuum International. 
Nevile, M. 2002. 'Coordinating talk and non-talk activity in the airline cockpit'. Australian Review of Applied Linguistics 25 (1): 131-146.

Nevile, M. 2004. Beyond the Black Box: Talk-in-Interaction in the Airline Cockpit. Aldershot, UK: Ashgate.

Nevile, M. 2005. 'Checklist complete. Or is it? Closing a task in the airline cockpit'. Australian Review of Applied Linguistics 28 (2): 60-76.

Pomerantz, A.; Fehr, B. J. 1997. 'Conversation analysis: An approach to the study of social action as sense making practices'. In Discourse as Social Interaction. Discourse Studies: A Multidisciplinary Introduction. Vol Two, edited by van Dijk, T. A. London: Sage.

Psathas, G. 1995. Conversation Analysis: The Study of Talk-in-Interaction. Thousand Oaks, California: Sage.

Rendle-Short, J. 1999. 'When "okay” is okay in computer science seminar talk'. Australian Review of Applied Linguistics 22 (2): 19-33.

Rendle-Short, J. 2003. 'So what does that show us?: Analysis of the discourse marker "so" in the academic monologue'. Australian Review of Applied Linguistics 26 (3): 46-62.

Rendle-Short, J. 2006. The Academic Presentation: Situated Talk in Action. Aldershot, UK: Ashgate.

Richards, K.; Seedhouse, P., editors. 2005. Applying Conversation Analysis. Houndmills, UK: Palgrave Macmillan.

Sacks, H. 1992. Lectures on Conversation. Two volumes. Edited by Gail Jefferson. Oxford: Basil Blackwell.

Sacks, H; Schegloff, E. A.; Jefferson, G. 1974. 'A simplest systematics for the organization of turn-taking for conversation'. Language 50 (4): 696-735.

Schegloff, E. A. 1996. 'Turn organization: One intersection of grammar and interaction'. In Interaction and Grammar, edited by Ochs, E., Schegloff, E. A.; Thompson, S. A. Cambridge: Cambridge University Press.

Schegloff, E. A. 2006. 'Interaction: The infrastructure for social institutions, the natural ecological niche for language, and the arena in which culture is enacted'. In Roots of Human Sociality: Culture, Cognition and Interaction, edited by Enfield, N. J.; Levinson, S. C. Oxford: Berg.

Schegloff, E. A. 2007. Sequence Organization in Interaction: A Primer in Conversation Analysis. Vol 1. Cambridge: Cambridge University Press.

Schegloff, E. A.; Koshik, I.; Jacoby, S.; Olsher, D. 2002. 'Conversation analysis and applied linguistics'. Annual Review of Applied Linguistics 22: 3-31.

Schegloff, E. A.; Sacks, H. 1973. 'Opening up closings'. Semiotica 8: 289-327.

Seedhouse, P. 2004. The Interactional Architecture of the Language Classroom: A Conversation Analysis Perspective. Malden, MA: Blackwell.

Silverman, D. 1998. Harvey Sacks: Social Science and Conversation Analysis. New York: Oxford University Press.

Smith, C. D. 1996. 'Competing constraints in alternative dispute resolution: The interactional achievement of formality and informality in mediation'. Australian Review of Applied Linguistics 19 (2): 79-114. 
So'o, A.; Liddicoat, A. 2000. 'Telephone openings in Samoan'. Australian Review of Applied Linguistics 23 (1): 95-107.

Taylor, E. 1994. 'Preference organization in teacher-supervisor talk'. In Spoken Interaction Studies in Australia, edited by Gardner, R. Australian Review of Applied Linguistics Series S 11: 137-152. Melbourne: Applied Linguistics Association of Australia.

Wagner, J. 1996. 'Foreign language acquisition through interaction'. Journal of Pragmatics 26: 215-235.

Wooffitt, R. 2005. Conversation Analysis and Discourse Analysis: A Comparative and Critical Introduction. London: Sage.

Cite this article as: Nevile, Maurice; Rendle-Short, Johanna. 2007. 'Language as action'. Australian Review of Applied Linguistics (special thematic issue Language as Action: Australian Studies in Conversation Analysis, edited by Rendle-Short, Johanna; Nevile, Maurice). 30 (3): pp. 30.1-30.13. DOI: 10.2104/aral0730. 